\title{
Nodule carbohydrate catabolism is enhanced in the Medicago truncatula A17-Sinorhizobium medicae WSM419 symbiosis
}

\section{Estíbaliz Larrainzar ${ }^{\dagger}$, Erena Gil-Quintana ${ }^{\dagger}$, Amaia Seminario, Cesar Arrese-Igor and Esther M. González*}

Departamento de Ciencias del Medio Natural/Environmental Sciences, Universidad Pública de Navarra, Pamplona, Spain

\author{
Edited by: \\ Monica Medina, Pennsylvania State \\ University, USA

\section{Reviewed by:} \\ Andrea Doris Nussbaumer, University \\ of Vienna, Austria \\ Jason Terpolilli, Murdoch University, \\ Australia

\section{*Correspondence:} \\ Esther M. González, Departamento \\ de Ciencias del Medio \\ Natural/Environmental Sciences, \\ Universidad Pública de Navarra, \\ Campus Arrosadia s/n, Pamplona, \\ Navarra 31006, Spain \\ e-mail: esther.gonzalez@unavarra.es \\ ${ }^{\dagger}$ Estíbaliz Larrainzar and Erena \\ Gil-Quintana have contributed equally \\ to this work.
}

\begin{abstract}
The symbiotic association between Medicago truncatula and Sinorhizobium meliloti is a well-established model system in the legume-Rhizobium community. Despite its wide use, the symbiotic efficiency of this model has been recently questioned and an alternative microsymbiont, S. medicae, has been proposed. However, little is known about the physiological mechanisms behind the higher symbiotic efficiency of S. medicae WSM419. In the present study, we inoculated $M$. truncatula Jemalong A17 with either S. medicae WSM419 or S. meliloti 2011 and compared plant growth, photosynthesis, $\mathrm{N}_{2}$-fixation rates, and plant nodule carbon and nitrogen metabolic activities in the two systems. $M$. truncatula plants in symbiosis with $S$. medicae showed increased biomass and photosynthesis rates per plant. Plants grown in symbiosis with S. medicae WSM419 also showed higher $\mathrm{N}_{2}$-fixation rates, which were correlated with a larger nodule biomass, while nodule number was similar in both systems. In terms of plant nodule metabolism, M. truncatula-S. medicaeWSM419 nodules showed increased sucrose-catabolic activity, mostly associated with sucrose synthase, accompanied by a reduced starch content, whereas nitrogenassimilation activities were comparable to those measured in nodules infected with $S$. meliloti 2011. Taken together, these results suggest that S. medicae WSM419 is able to enhance plant carbon catabolism in $M$. truncatula nodules, which allows for the maintaining of high symbiotic $\mathrm{N}_{2}$-fixation rates, better growth and improved general plant performance.
\end{abstract}

Keywords: Medicago truncatula, Sinorhizobium medicae, Sinorhizobium meliloti, symbiosis, efficiency, nitrogen fixation, carbon metabolism

\section{INTRODUCTION}

One of the most studied plant-microbe symbiosis is the one established between members of the Leguminosae family and soil bacteria from diverse genera collectively termed rhizobia. When compatible symbiotic partners interact, the microsymbiont is able to invade the host root hair cells, typically (but not exclusively) through infection threads, reaching the root cortex, where they are released and differentiate into nitrogen-fixing forms; the bacteroids. In such differentiated forms, bacteria express an enzyme complex, the nitrogenase, which catalyzes the reduction of atmospheric dinitrogen $\left(\mathrm{N}_{2}\right)$ to ammonium during the highly energy-demanding process known as symbiotic $\mathrm{N}_{2}$-fixation. During this complex symbiotic interaction the plant provides a carbon source, mainly in the form of malate (Udvardi et al., 1988), to be used as a respiratory substrate to fuel the $\mathrm{N}_{2}$-fixation process (Lodwig and Poole, 2003). Symbiotic $\mathrm{N}_{2}$-fixation is estimated to contribute to nearly half of the global biological $\mathrm{N}_{2}$-fixation reactions worldwide, representing a key process for sustainable natural and agricultural systems (Gruber and Galloway, 2008).

In recent years Medicago truncatula (barrel medic) has been one of the model legume species most widely studied by the symbiotic community (Barker et al., 1990; Cook, 1999). The development of mutant collections (Tadege et al., 2008; Calderini et al., 2011), optimization of transformation techniques (Boisson-Dernier et al.,
2001) and availability of its genome sequence (Young et al., 2011) have greatly contributed to progress in the field.

So far at least two Sinorhizobium [renamed Ensifer (Young, 2003)] species have been described to nodulate Medicago spp: Sinorhizobium meliloti and S. medicae (Rome et al., 1996a). Although $M$. truncatula is able to establish $\mathrm{N}_{2}$-fixing symbiosis with both symbionts, most plant molecular biology studies have been carried out using the sequenced S. meliloti 1021 strain (Galibert et al., 2001). In recent years, however, the suitability of the M. truncatula-S. meliloti model has been questioned based on evidences that suggest that $\mathrm{N}_{2}$-fixation in this model is only partially effective (Moreau et al., 2008; Terpolilli et al., 2008). Instead, S. medicae WSM419, for which genomic sequence is also available (Reeve et al., 2010), has been suggested as a more efficient symbiont for M. truncatula (Terpolilli et al., 2008).

Phylogenetic analysis has shown that $S$. meliloti and S. medicae form a tight cluster within the Sinorhizobium group (Gaunt et al., 2001). Furthermore, application of several molecular markers to genetically analyze this relationship suggests that $S$. medicae was originated from an ancestral S. meliloti population (Biondi et al., 2003). Nowadays, these rhizobial species can be differentiated both at the phenotypic and genotypic level: $S$. meliloti is more specific for the tetraploid M. sativa and is preferentially found in alkaline or neutral soils, while S. medicae prefers diploid Medicago 
species such as M. truncatula and is predominantly found in moderately acid environments (Biondi et al., 2003; Garau et al., 2005). These host and environment preferences may have been a consequence of the various interspecific horizontal gene transfers that occurred during species diversification (Bailly et al., 2007; Epstein et al., 2014).

Nevertheless, to date, the physiological mechanisms underlying the higher symbiotic efficiency in the M. truncatula A17-S. medicae WSM419 association remain largely unknown. Comparative genomic studies of multiple $S$. meliloti and $S$. medicae strains have shed some light, suggesting that differences in gene content between the two species, particularly in genes involved in sulfur assimilation, conjugation and secretion, can be related to the differential symbiotic interaction and $\mathrm{N}_{2}$-fixation efficiency (Sugawara et al., 2013). Understanding which are the factors that underpin $\mathrm{N}_{2}$-fixation efficiency in legumes has potentially profound implications for sustainable agricultural systems and the environment.

In the current work, we analyzed the differences at the physiological and metabolic levels between the currently established model M. truncatula-S. meliloti and the more efficient $M$. truncatula-S. medicae symbiosis. We hypothesized that plant nodule metabolism may be enhanced in the $S$. medicae symbiosis compared to less efficient strains. To test this hypothesis, two sets of $M$. truncatula Jemalong A17 plants were grown under symbiotic conditions either with S. meliloti 2011 or S. medicae WSM419. Plant growth parameters, photosynthesis, $\mathrm{N}_{2}$-fixation, and plant nodule carbon and nitrogen metabolic activities were determined. Results presented here show that S. medicae WSM419-derived nodules generate a stronger sink in the plant, through the activation of sucrose-hydrolyzing enzymes. This allows the maintenance of high $\mathrm{N}_{2}$-fixation rates, increased nodule growth, and, therefore, a generally improved plant performance.

\section{MATERIALS AND METHODS GROWTH CONDITIONS}

Medicago truncatula Gaertn cv. Jemalong A17 plants were grown in 1-L pots with a mixture of perlite:vermiculite $(2: 5, \mathrm{v} / \mathrm{v})$ as substrate under controlled environmental conditions ( $14 \mathrm{~h}$ day/10 h night; $450 \mu \mathrm{mol} \mathrm{m}{ }^{-2} \mathrm{~s}^{-1}$ light intensity; $22^{\circ} \mathrm{C} / 16^{\circ} \mathrm{C}$ day/night temperature; $60-70 \%$ relative humidity). After germination, plantlets were separated into two sets: one was inoculated with $S$. meliloti strain 2011 (Meade and Signer, 1977) and the other was inoculated with S. medicae strain WSM419 (Rome et al., 1996b). Bacterial cultures were grown on a rotary shaker $(175 \mathrm{rpm})$ at $28^{\circ} \mathrm{C}$ for $48 \mathrm{~h}$ in yeast extract mannitol broth containing $\left(g \mathrm{~L}^{-1}\right) \mathrm{K}_{2} \mathrm{HPO}_{4}(0.5), 0.2 \mathrm{MgSO}_{4} \cdot 7 \mathrm{H}_{2} \mathrm{O}, \mathrm{NaCl}(0.1)$, mannitol (10), and yeast extract $(0.4), \mathrm{pH}$ adjusted to 6.8 , to an $\mathrm{OD}_{600}$ of $0.7-0.8$, which corresponds to $\sim 3 \times 10^{8}$ cells (Vincent, 1970). $1 \mathrm{ml}$ of the cultures was inoculated onto each seedling at sowing.

Plants were watered with a nutrient solution containing (values in $\mathrm{mg} \mathrm{L}^{-1}$ ): $\mathrm{MgSO}_{4} \cdot 7 \mathrm{H}_{2} \mathrm{O}$ (493), $\mathrm{K}_{2} \mathrm{SO}_{4}$ (279), $\mathrm{K}_{2} \mathrm{HPO}_{4}$ (145), $\mathrm{CaCl}_{2}$ (56), $\quad \mathrm{KH}_{2} \mathrm{PO}_{4}$ (23), EDTA-Fe (17), $\mathrm{H}_{3} \mathrm{BO}_{3}$ (1.43), $\mathrm{CaSO}_{4} \cdot 2 \mathrm{H}_{2} \mathrm{O}(1.03), \mathrm{MnSO}_{4} \cdot 7 \mathrm{H}_{2} \mathrm{O}(0.77), \mathrm{ZnSO}_{4} \cdot 7 \mathrm{H}_{2} \mathrm{O}$ (0.22), $\mathrm{CoCl}_{2} \cdot 6 \mathrm{H}_{2} \mathrm{O}(0.12), \mathrm{CuSO}_{4} \cdot 5 \mathrm{H}_{2} \mathrm{O}(0.08), \mathrm{NaMoO}_{4} \cdot 2 \mathrm{H}_{2} \mathrm{O}$ (0.05). For the first 3 weeks, $0.25 \mathrm{mM}$ ammonium nitrate was added to the nutrient solution. Eight weeks after planting, symbiotic $\mathrm{N}_{2}$-fixation was measured, nodules collected, divided into aliquots, frozen in liquid $\mathrm{N}_{2}$ and stored at $-80^{\circ} \mathrm{C}$ for analytical determinations. Two nodule aliquots per plant were used for nodule number estimation based on total nodule weight. Shoots and roots were weighed for fresh weight (FW) determinations and, subsequently, oven-dried at $80^{\circ} \mathrm{C}$ for $48 \mathrm{~h}$ before dry weight (DW) was measured.

\section{NITROGEN FIXATION AND CHLOROPHYLL CONTENT DETERMINATIONS}

Symbiotic $\mathrm{N}_{2}$-fixation was measured in intact plants as apparent nitrogenase activity (ANA). $\mathrm{H}_{2}$ evolution from sealed roots systems was measured in an open flow-through system under $\mathrm{N}_{2}: \mathrm{O}_{2}$ (79\%:21\%, v/v) according to Witty and Minchin (1998) using an electrochemical $\mathrm{H}_{2}$-sensor (Qubit System, Canada).

Photosynthesis was determined in the apical leaves with an open system mode (model LC pro+; ADC BioScientific Ltd., Great Amwell, UK) using an ADC PLC-7504 leaf chamber. To estimate leaf chlorophyll content a Minolta SPAD-502 system was employed (Konica Minolta Sensing Europe BV, UK).

\section{NODULE PROTEIN EXTRACTION AND ENZYMES ASSAY}

Nodules (100 mg FW) were homogenized in a mortar and pestle with 500-600 $\mu \mathrm{L}$ of extraction buffer $(50 \mathrm{mM} \mathrm{3-}(\mathrm{N}-$ morpholino)propanesulfonic acid (MOPS), $5 \mathrm{mM} \mathrm{MgCl}_{2}, 20 \mathrm{mM}$ $\mathrm{KCl}, 1 \mathrm{mM}$ EDTA, 20\% polyvinylpolypyrrolidone, $\mathrm{pH} 7$ ) where $1.5 \mathrm{mg} \mathrm{mL}^{-1}$ of DTT, $0.7 \mu \mathrm{L} \mathrm{mL}^{-1}$ of $\beta$-mercaptoethanol and $20 \mu \mathrm{L} \mathrm{mL} \mathrm{m}^{-1}$ plant protease inhibitor cocktail (Sigma-Aldrich) were freshly added. Homogenates were centrifuged at 12,000 $\mathrm{g}$ and $4^{\circ} \mathrm{C}$ for $15 \mathrm{~min}$ and supernatants were collected as nodule plant fractions. The nodule plant fraction was desalted using Bio Gel P6DG columns (Bio-Rad) equilibrated with $250 \mathrm{mM}$ MOPS (pH 7), $100 \mathrm{mM} \mathrm{KCl}$ and $25 \mathrm{mM} \mathrm{MgCl}_{2}$. The desalted extract was used to measure the following enzyme activities according to Gonzalez et al. (1998): sucrose synthase (EC 2.4.1.13), alkaline invertase (EC 3.2.1.26), NADH-dependent glutamate synthase (GOGAT; EC 1.4.1.14), and aspartate aminotransferase (AAT; EC 2.6.1.1). The protein content in crude and desalted extracts was quantified using a Bradford-based dye-binding assay (Bio-Rad) employing bovine serum albumin as standard.

\section{CARBOHYDRATE AND STARCH DETERMINATION}

$100 \mathrm{mg}$-FW nodule aliquots were extracted in $80 \%(\mathrm{v} / \mathrm{v})$ ethanol and ultrasonicated in a water bath system. After sonication, samples were centrifuged at 7,500 $\mathrm{g}$ and $4^{\circ} \mathrm{C}$ for $5 \mathrm{~min}$ and supernatants were collected. These steps were repeated three times. Afterward the supernatants were dried in a Turbovap LV evaporator (Zymark Corp, Hopkinton, MA, USA) and soluble compounds were redissolved in $1 \mathrm{~mL}$ distilled water, homogenized and stored at $-20^{\circ} \mathrm{C}$. The ethanol-insoluble residue was extracted for starch determination as in Macrae (1971). Carbohydrates were analyzed by high-performance capillary electrophoresis (Warren and Adams, 2000) using $10 \mathrm{mM}$ benzoate ( $\mathrm{pH} \mathrm{12)} \mathrm{containing} 0.5 \mathrm{mM}$ myristyltrimethylammonium bromide as a buffer under the following conditions: $-15 \mathrm{kV}$ potential, $50 \mu \mathrm{m}$-internal diameter and 30/40.2 cm-long capillary tube, indirect UV detection at $225 \mathrm{~nm}$. 


\section{STATISTICAL ANALYSIS}

All data are reported as mean \pm standard deviation of $n=5$ independent measurements. Statistical analysis was conducted using Student's $t$-test and $p \leq 0.05$ was considered as statistically significant. The homogeneity of variances was tested using Levene's test.

\section{RESULTS}

In general terms, $M$. truncatula plants inoculated with $S$. medicae WSM419 outperformed those inoculated with S. meliloti 2011. Total plant biomass in the M. truncatula-S. medicae system was more than two-fold higher than when using the S. meliloti strain and the difference was most notable for shoots (Figure 1; Table 1). Plants inoculated with the $S$. medicae strain maintained a 1:1 shoot-to-root ratio, while this declined to $\sim 3: 4$ in plants inoculated with S. meliloti 2011 (Table 1).

Regarding photosynthetic $\mathrm{CO}_{2}$ assimilation, M. truncatula-S. medicae plants showed a $55.8 \%$ increase in photosynthesis when

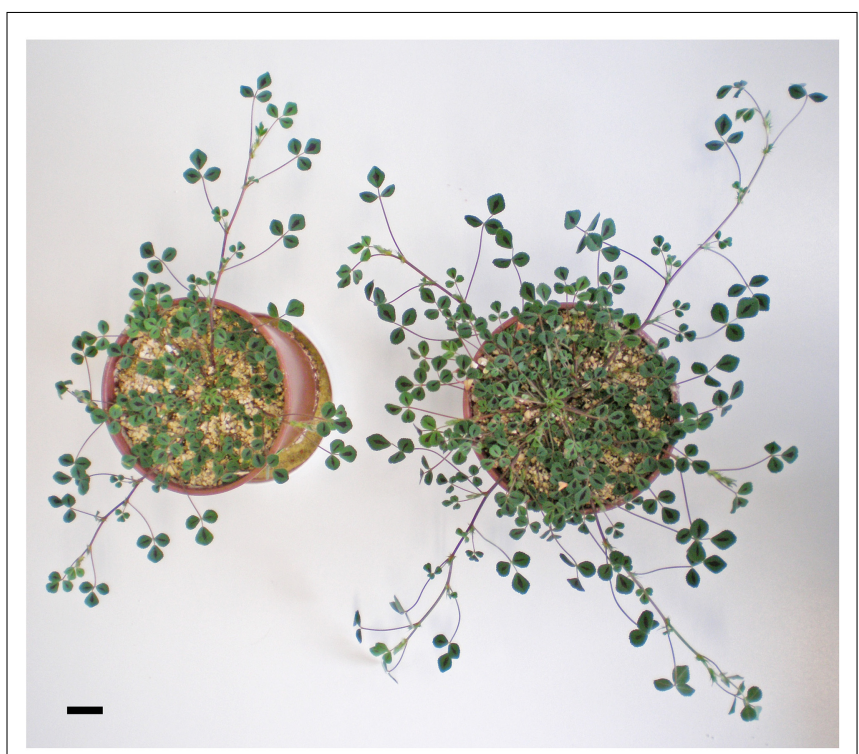

FIGURE 1 | Medicago truncatula cv. Jemalong A17 plants 8 weeks after inoculation with either Sinorhizobium meliloti 2011 (left) or Sinorhizobium medicae WSM419 (right). Scale bar $=2 \mathrm{~cm}$

Table 1 | Plant biomass.

\begin{tabular}{lll}
\hline Biomass (g FW) & $\begin{array}{l}\text { M. truncatula-S. } \\
\text { meliloti } 2011\end{array}$ & $\begin{array}{l}\text { M. truncatula-S. } \\
\text { medicae WSM419 }\end{array}$ \\
\hline Shoot & $9.10 \pm 1.81$ & $26.48 \pm 1.00^{*}$ \\
Root & $12.85 \pm 2.55$ & $25.70 \pm 2.73^{*}$ \\
Total plant & $22.40 \pm 4.43$ & $52.95 \pm 2.66^{*}$ \\
Shoot:root ratio & $0.71 \pm 0.02$ & $1.08 \pm 0.13^{*}$ \\
\hline
\end{tabular}

M. truncatula plant biomass values when grown in symbiosis with $S$. melilot 2011 or S. medicae WSM419. Values are mean \pm standard deviation of five biological replicates. An asterisk (*) denotes significant differences (Student's t-test at $p \leq 0.05)$. FW $=$ fresh weight expressed on a plant basis (Figure 2A). However, when expressed on a leaf area basis, $M$. truncatula-S. meliloti showed higher photosynthetic rates $\left(86.37 \pm 2.09 \mu \mathrm{mol} \mathrm{CO}_{2} \mathrm{~s}^{-1} \mathrm{~cm}^{-2}\right)$ compared to S. medicae-inoculated plants $\left(67.19 \pm 2.43 \mu \mathrm{mol} \mathrm{CO}_{2} \mathrm{~s}^{-1} \mathrm{~cm}^{-2}\right)$. These higher photosynthetic rates were, however, not correlated with increased leaf chlorophyll content values, with both plant systems presenting similar values (Figure 2B).

To accurately estimate the rates of $\mathrm{N}_{2}$-fixation, ANA was measured as $\mathrm{H}_{2}$ evolution in intact plants (Witty and Minchin, 1998). The M. truncatula-S. medicae symbiosis showed increased $\mathrm{N}_{2}$-fixation values both when expressed on a plant $(+57 \%)$ and nodule FW basis (Figure 3A). Plants inoculated with S. medicae showed higher nodule biomass (Figure 3B), although the number of root nodules was similar in both cases (Figure 3C). The increase in nodule biomass was, therefore, correlated with higher biomass per nodule. Plants inoculated with the $S$. medicae strain presented larger and more frequently bifurcated nodules compared to plants inoculated with the $S$. meliloti strain (Figure 3D). Furthermore, the plant fraction of M. truncatula$S$. medicae nodules showed a significantly higher protein content than that of nodules infected with $S$. meliloti $(25.18 \pm 3.32$ vs. $20.53 \pm 3.58 \mathrm{mg}$ protein $\mathrm{g} \mathrm{FW}^{-1}$, mean \pm standard deviation, respectively).

To better understand the metabolic differences in nodules following inoculation with the two microsymbionts, we measured the activity of the two main sucrose-degrading enzymes in nodules, sucrose synthase and alkaline invertase, as well as the activity of two key enzymes involved in ammonium assimilation, GOGAT and AAT. In both systems the specific activity of sucrose synthase was on average more than 25 -fold higher than that of alkaline invertase (data not shown). Comparing the activity levels across systems, only sucrose synthase showed a significant increase in S. medicae-infected nodules (Figure 4A). In terms of nodule nitrogen metabolism, neither GOGAT nor AAT activities showed significantly different rates when comparing the two inoculants (data not shown).

Given that nodule sucrose catabolism was found to be more active in the M. truncatula-S. medicae symbiosis, the main carbon metabolites in nodules were quantified; sucrose and starch (Figures 4B,C). As a general trend, S. medicae-infected nodules presented lower levels of carbohydrates compared to those infected by the S. meliloti strain, with significant differences found in terms of starch content (Figure 4C).

\section{DISCUSSION}

The efficiency of a legume-Rhizobium symbiosis is usually evaluated by comparing plant growth parameters (e.g., biomass, $\mathrm{N}$ content) of inoculated versus $\mathrm{N}$-fed plants. These types of study, mostly analyzed from the bacterial perspective, have demonstrated that symbiotic efficiency varies depending upon the specific bacterial strain used (Miller and Sirois, 1982; Mhadhbi et al., 2005; Parra-Colmenares and Kahn, 2005; Heath and Tiffin, 2007; Rangin et al., 2008; Terpolilli et al., 2008; Oono and Denison, 2010). However, the plant contribution to these variable efficiencies has received much less attention.

In this work, we analyzed the effectiveness of the symbiosis of M. truncatula A17 with two Sinorhizobium strains, S. meliloti 

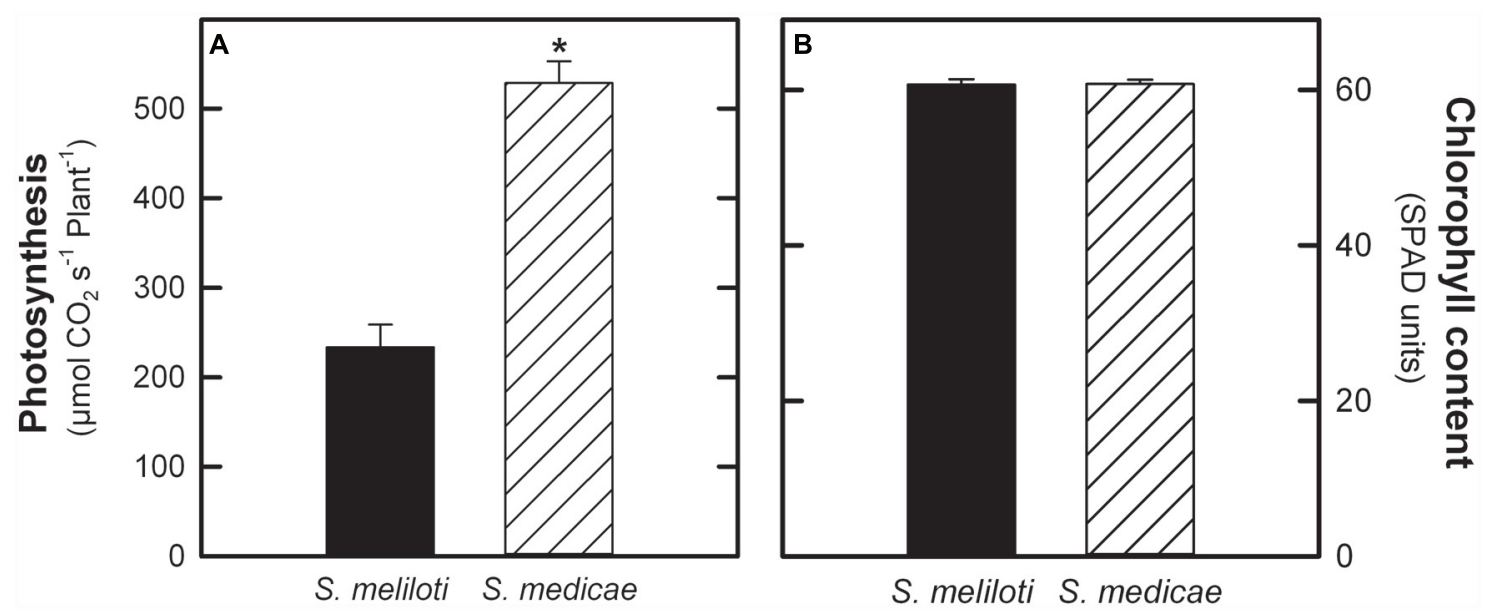

FIGURE 2 | Photosynthesis rates (A) and chlorophyll content (B) in M. truncatula inoculated with either S. meliloti 2011 or S. medicae WSM419. Values represent mean \pm standard deviation $(n=5)$. An asterisk $\left(^{*}\right)$ denotes significant differences (Student's $t$-test at $\left.p \leq 0.05\right)$.
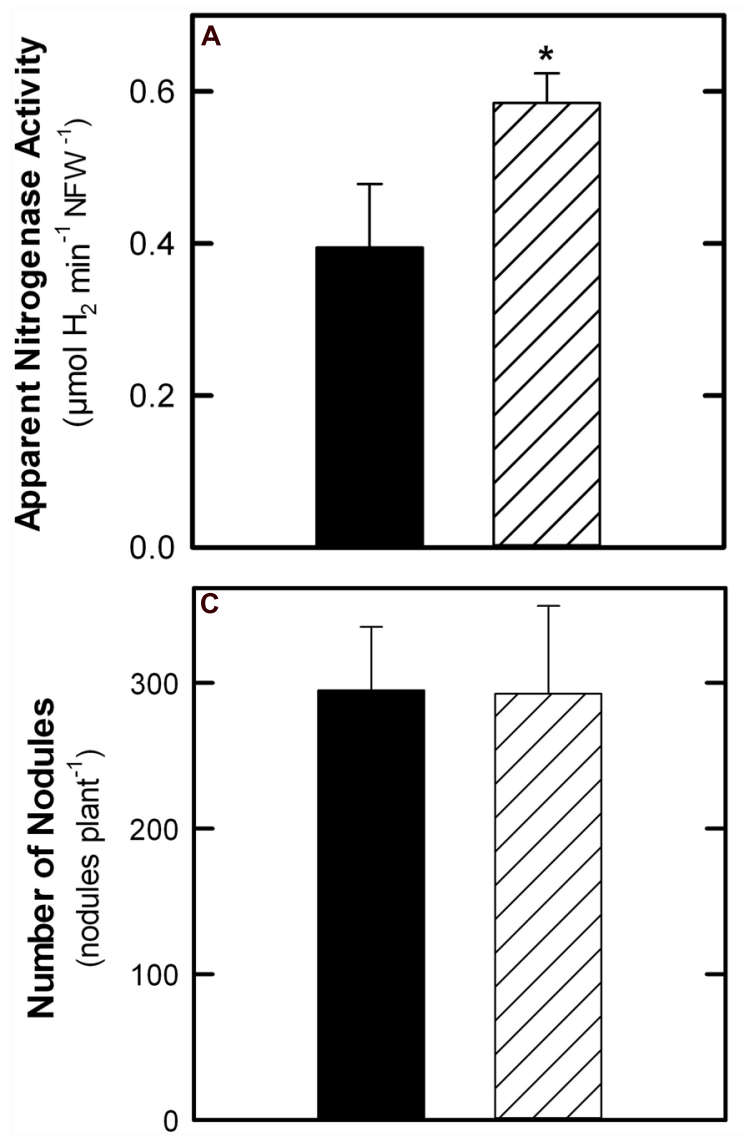

FIGURE 3 | $\mathrm{N}_{2}$-fixation rates measured as apparent nitrogenase activity (ANA, A), total nodule biomass (B), nodule number (C) in $M$. truncatula plants inoculated with either S. meliloti 2011 or S. medicae WSM419. D, representative image of nodules sampled from

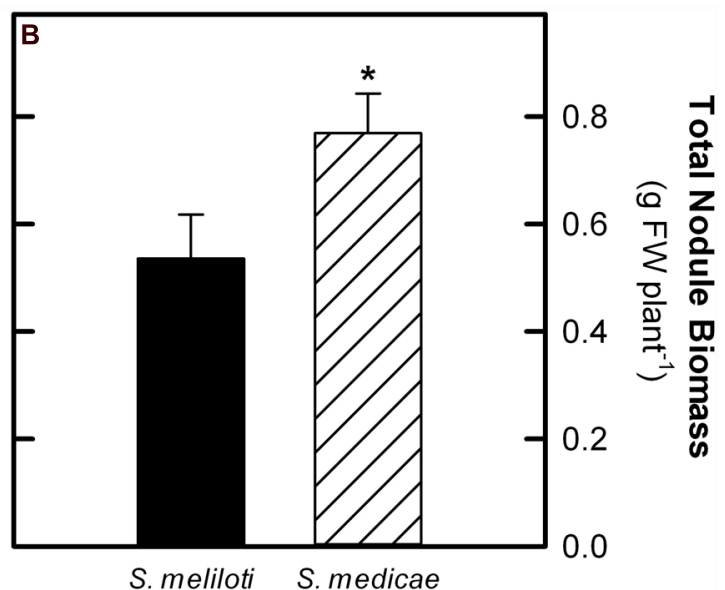

D

S. meliloti S. medicae

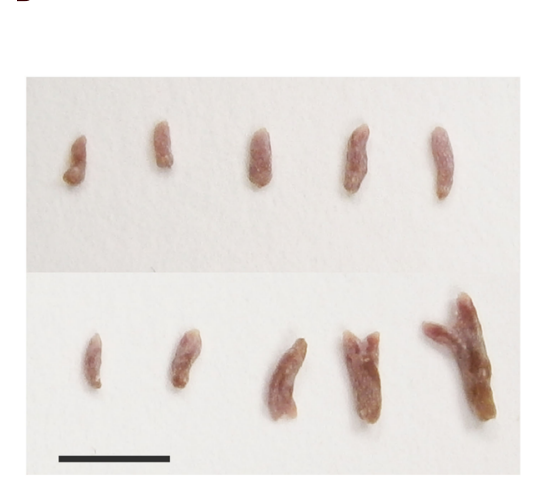

plants inoculated with S. meliloti 2011 (top) or S. medicae WSM419 (bottom). Scale bar $=500 \mu \mathrm{m}$. Values represent mean \pm standard deviation $(n=5)$. An asterisk $\left({ }^{*}\right)$ denotes significant differences $(p \leq 0.05)$. 

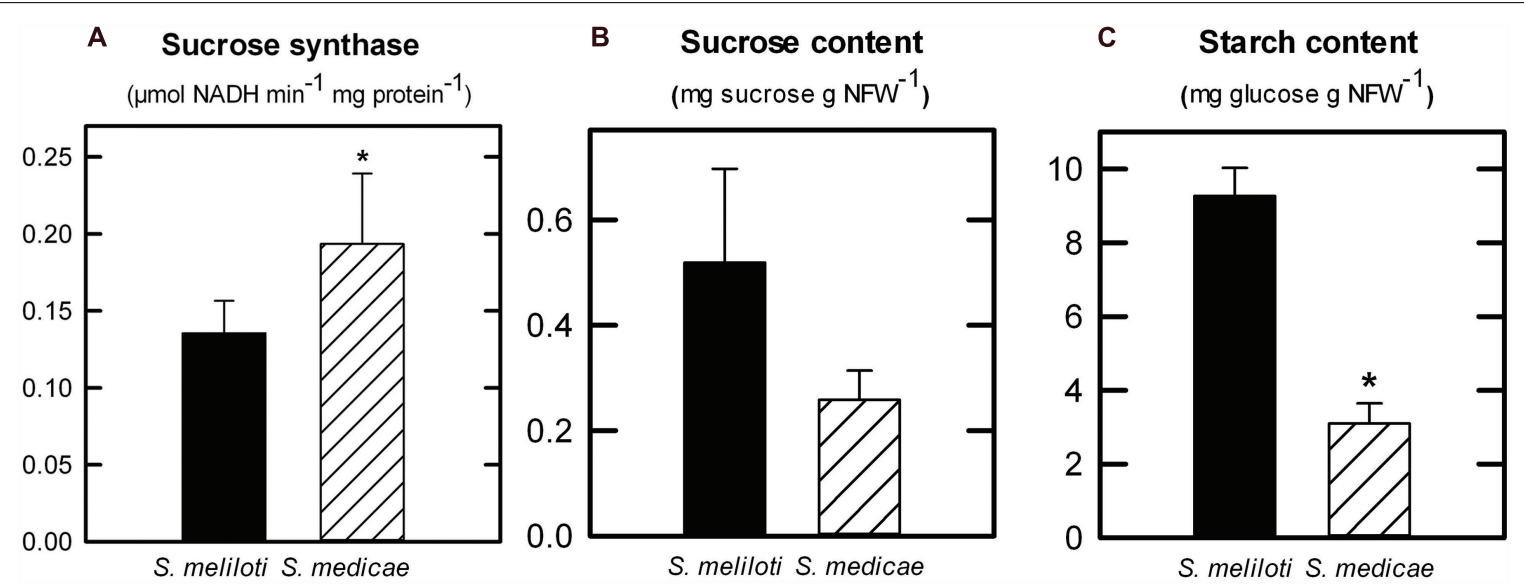

FIGURE 4 | Sucrose synthase (A) enzymatic activity in $M$. truncatula nodules inoculated with either S. meliloti 2011 or S. medicae WSM419. Values are given in $\mu \mathrm{mol} \mathrm{NADH}$ min $^{-1} \mathrm{mg}$ plant protein ${ }^{-1}$ and represent mean \pm standard deviation $(n=5)$. Sucrose $(\mathbf{B})$ and starch content $(\mathbf{C})$ in $M$. truncatula nodules inoculated with either S. meliloti 2011 or S. medicae WSM419. Values (in $\mathrm{mg} \mathrm{g} \mathrm{NFW}^{-1}$ ) represent mean \pm standard deviation of five biological replicates. An asterisk $\left({ }^{*}\right)$ denotes significant differences $(p \leq 0.05)$.
2011 and S. medicae WSM419, with special emphasis on understanding the main differences at the nodule metabolic level. Under our experimental growth conditions, M. truncatula plants grown almost exclusively on fixed $\mathrm{N}$ upon inoculation with $S$. meliloti 2011 did not show symptoms of $\mathrm{N}$ deficiency, presenting leaf chlorophyll contents comparable to those of plants inoculated with the $S$. medicae strain (Figure 2B). We did, however, observe a general outperformance of plants inoculated with the $S$. medicae strain in terms of plant biomass (Figure 1; Table 1), photosynthesis per plant (Figure 2A) and $\mathrm{N}_{2}$-fixation rates (Figure 3A). Interestingly, this improved fixation performance was correlated with a larger biomass per nodule, leading to a higher total nodule biomass per plant, but not to increased nodule number (Figure 3).

Nodules are strong sink tissues due to the high-energy demand that symbiotic $\mathrm{N}_{2}$-fixation represents for the plant (Silsbury, 1977; Schuize et al., 1999). These high-energy requirements are met by allocating photoassimilates from the aerial part to nodules, mostly in the form of sucrose, where they are hydrolyzed by either sucrose synthase or alkaline invertase (Morell and Copeland, 1984; Flemetakis et al., 2006). Sucrose synthase is considered to be primarily responsible for sucrose metabolism in mature nodules and its role has been shown to be essential for symbiotic $\mathrm{N}_{2}$ fixation in legumes (Gordon et al., 1999; Baier et al., 2007; Horst et al., 2007), while alkaline invertase appears to have a secondary role (Welham et al., 2009). In this study, the predominant role of sucrose synthase as the main sucrose-degrading enzyme in nodules was corroborated, showing a significantly higher specific activity than that of alkaline invertase in both symbiotic systems ( $>20$-fold higher in average). Nodules from plants inoculated with the more efficient $S$. medicae strain showed higher sucrose synthase activity compared to S. meliloti 2011 nodules (Figure 4A). Furthermore, S. medicae WSM419-inoculated plants maintained nodule starch at significantly lower levels compared to those inoculated with the S. meliloti strain (Figure 4C), despite the higher photosynthetic rates of the former (Figure 2A). This inverse correlation between symbiotic efficiency and starch accumulation has been similarly observed in alfalfa plants when inoculated with a fix strain (Aleman et al., 2010). Indeed, in non-fixing alfalfa nodules, the products from sucrose breakdown are re-directed to starch biosynthesis due to the lower energy demand. Taken together, these results suggest that $S$. medicae WSM419 activates plant carbon catabolic reactions in nodules to keep up with the high nitrogenase demand for ATP and, as a consequence, they become stronger metabolic sinks in the plant (Sung et al., 1989). This positive feedback keeps $\mathrm{N}_{2}$-fixation rates high, promoting plant growth and, therefore, increasing the plant photosynthetic capacity. A similar mechanism has been described when bacteroid respiration is enhanced in nodules by the overexpression of a cytochrome oxidase (Soberon et al., 1999; Silvente et al., 2002; Talbi et al., 2012).

Despite the differences in $\mathrm{N}_{2}$-fixation rates, plants inoculated with the $S$. meliloti strain did not show significant differences in terms of nodule number (Figure 3C). Differences were, however, found in the plant protein fraction of nodules, most likely related to the metabolic activation discussed above. It is interesting, though, that these differences are mostly observed at the level of carbon metabolism, while the specific activity of enzymes involved in $\mathrm{N}$ assimilation did not differ significantly when the two symbiotic systems were compared (data not shown).

In conclusion, results presented here suggest that at least one of the factors contributing to the higher effectiveness of the $M$. truncatula-S. medicae WSM419 symbiosis is the activation of plant carbon catabolism in nodules, which allows the maintenance of high $\mathrm{N}_{2}$-fixation rates and, ultimately, leads to an improved plant performance. In agreement with previous studies (Moreau et al., 2008; Terpolilli et al., 2008), the use of S. medicae WSM419 as the partner of choice for M. truncatula symbiotic studies is highly recommended.

\section{ACKNOWLEDGMENTS}

We thank Dr. Euan K. James (The James Hutton Institute, Dundee, UK) and Dr. Jason J. Terpolilli (Murdoch University, Western Australia, Australia) for sharing the S. medicae WSM419 
strain, and Dr. Gustavo Garijo for technical assistance. This work has been partially funded by the Spanish National Research and Development Programmes (AGL2011-23738 and AGL201130386-C02-01). Estíbaliz Larrainzar and Erena Gil-Quintana are funded by the European FP7-PEOPLE program (253141). Amaia Seminario is funded by a predoctoral fellowship from the Public University of Navarre.

\section{REFERENCES}

Aleman, L., Ortega, J. L., Martinez-Grimes, M., Seger, M., Holguin, F. O., Uribe, D. J., et al. (2010). Nodule-enhanced expression of a sucrose phosphate synthase gene member (MsSPSA) has a role in carbon and nitrogen metabolism in the nodules of alfalfa (Medicago sativa L.). Planta 231, 233-244. doi: 10.1007/s00425-0091043-y

Baier, M. C., Barsch, A., Kuster, H., and Hohnjec, N. (2007). Antisense repression of the Medicago truncatula nodule-enhanced sucrose synthase leads to a handicapped nitrogen fixation mirrored by specific alterations in the symbiotic transcriptome and metabolome. Plant Physiol. 145, 1600-1618. doi: 10.1104/pp.107.106955

Bailly, X., Olivieri, I., Brunel, B., Cleyet-Marel, J. C., and Béna, G. (2007). Horizontal gene transfer and homologous recombination drive the evolution of the nitrogen-fixing symbionts of Medicago species. J. Bacteriol. 189, 5223-5236. doi: 10.1128/JB.00105-07

Barker, D. G., Bianchi, S., Blondon, F., Dattee, Y., Duc, G., Essad, S., et al. (1990). Medicago truncatula, a model plant for studying the molecular genetics of the Rhizobium-legume symbiosis. Plant Mol. Biol. Rep. 8, 40-49. doi: 10.1007/BF02668879

Biondi, E. G., Pilli, E., Giuntini, E., Roumiantseva, M. L., Andronov, E. E., Onichtchouk, O. P., et al. (2003). Genetic relationship of Sinorhizobium melilot and Sinorhizobium medicae strains isolated from Caucasian region. FEMS Microbiol. Lett. 220, 207-213. doi: 10.1016/S0378-1097(03)00098-3

Boisson-Dernier, A., Chabaud, M., Garcia, F., Becard, G., Rosenberg, C., and Barker, D. G. (2001). Agrobacterium rhizogenes-transformed roots of Medicago truncatula for the study of nitrogen-fixing and endomycorrhizal symbiotic associations. Mol. Plant Microbe Interact. 14, 695-700. doi: 10.1094/MPMI.2001.14. 6.695

Calderini, O., Carelli, M., Panara, F., Biazzi, E., Scotti, C., Tava, A., et al. (2011). Collection of mutants for functional genomics in the legume Medicago truncatula. Plant Genet. Resour. 9, 174-176. doi: 10.1017/S1479262111000165

Cook, D. R. (1999). Medicago truncatula- a model in the making! Curr. Opin. Plant Biol. 2, 301-304. doi: 10.1016/S1369-5266(99)80053-3

Epstein, B., Sadowsky, M. J., and Tiffin, P. (2014). Selection on horizontally transferred and duplicated genes in Sinorhizobium (Ensifer), the root-nodule symbionts of Medicago. Genome Biol. Evol. 6, 1199-1209. doi: 10.1093/gbe/evu090

Flemetakis, E., Efrose, R. C., Ott, T., Stedel, C., Aivalakis, G., Udvardi, M. K., et al. (2006). Spatial and temporal organization of sucrose metabolism in Lotus japonicus nitrogen-fixing nodules suggests a role for the elusive alkaline. Plant Mol. Biol. 62, 53-69. doi: 10.1007/s11103-006-9003-4

Galibert, F., Finan, T. M., Long, S. R., Puhler, A., Abola, P., Ampe, F., et al. (2001). The composite genome of the legume symbiont Sinorhizobium meliloti. Science 293, 668-672. doi: 10.1126/science.1060966

Garau, G., Reeve, W. G., Brau, L., Deiana, P., Yates, R. J., James, D., et al. (2005) The symbiotic requirements of different Medicago spp. suggest the evolution of Sinorhizobium meliloti and S. medicae with hosts differentially adapted to soil $\mathrm{pH}$. Plant Soil 276, 263-277. doi: 10.1007/s11104-005-0374-0

Gaunt, M. W., Turner, S. L., Rigottier-Gois, L., Lloyd-Macgilp, S. A., and Young, J. P. (2001). Phylogenies of atpD and recA support the small subunit rRNAbased classification of rhizobia. Int. J. Syst. Evol. Microbiol. 51, 2037-2048. doi: 10.1099/00207713-51-6-2037

Gonzalez, E. M., Aparicio-Tejo, P. M., Gordon, A. J., Minchin, F. R., Royuela, M., and Arrese-Igor, C. (1998). Water-deficit effects on carbon and nitrogen metabolism of pea nodules. J. Exp. Bot. 49, 1705-1714. doi: 10.1093/jxb/49.327.1705

Gordon, A. J., Minchin, F. R., James, C. L., and Komina, O. (1999). Sucrose synthase in legume nodules is essential for nitrogen fixation. Plant Physiol. 120, 867-877. doi: $10.1104 /$ pp. 120.3 .867

Gruber, N., and Galloway, J. N. (2008). An Earth-system perspective of the global nitrogen cycle. Nature 451, 293-296. doi: 10.1038/nature06592
Heath, K. D., and Tiffin, P. (2007). Context dependence in the coevolution of plant and rhizobial mutualists. Proc. Biol. Sci. 274, 1905-1912. doi: 10.1098/rspb.2007.0495

Horst, I., Welham, T., Kelly, S., Kaneko, T., Sato, S., Tabata, S., et al. (2007). TILLING mutants of Lotus japonicus reveal that nitrogen assimilation and fixation can occur in the absence of nodule-enhanced sucrose synthase. Plant Physiol. 144, 806-820. doi: 10.1104/pp.107.097063

Lodwig, E., and Poole, P. (2003). Metabolism of Rhizobium bacteroids. Crit. Rev. Plant Sci. 22, 37-78. doi: 10.1080/713610850

Macrae, J. C. (1971). Quantitative measurement of starch in very small amounts of leaf tissue. Planta 96, 101-108. doi: 10.1007/BF00386360

Meade, H. M., and Signer, E. R. (1977). Genetic mapping of Rhizobium meliloti. Proc. Natl. Acad. Sci. U.S.A. 74, 2076-2078. doi: 10.1073/pnas.74.5.2076

Mhadhbi, H., Jebara, M., Limam, F., Huguet, T., and Aouani, M. E. (2005). Interaction between Medicago truncatula lines and Sinorhizobium meliloti strains for symbiotic efficiency and nodule antioxidant activities. Physiol. Plant. 124, 4-11. doi: 10.1111/j.1399-3054.2005.00489.x

Miller, R. W., and Sirois, J. C. (1982). Relative efficacy of different alfalfa cultivarRhizobium meliloti strain combinations for symbiotic nitrogen fixation. Appl. Environ. Microbiol. 43, 764-768.

Moreau, D., Voisin, A. S., Salon, C., and Munier-Jolain, N. (2008). The model symbiotic association between Medicago truncatula cv. Jemalong and Rhizobium meliloti strain 2011 leads to $\mathrm{N}$-stressed plants when symbiotic N2 fixation is the main N source for plant growth. J. Exp. Bot. 59, 3509-3522. doi: 10.1093/jxb/ ern203

Morell, M., and Copeland, L. (1984). Enzymes of sucrose breakdown in soybean nodules: alkaline invertase. Plant Physiol. 74, 1030-1034. doi: 10.1104/pp.74.4.1030

Oono, R., and Denison, R. F. (2010). Comparing symbiotic efficiency between swollen versus nonswollen rhizobial bacteroids. Plant. Physiol. 154, 1541-1548. doi: 10.1104/pp.110.163436

Parra-Colmenares, A., and Kahn, M. L. (2005). Determination of nitrogen fixation effectiveness in selected Medicago truncatula isolates by measuring nitrogen isotope incorporation into pheophytin. Plant Soil 270, 159-168. doi: 10.1007/s11104-004-1308-y

Rangin, C., Brunel, B., Cleyet-Marel, J. C., Perrineau, M. M., and Béna, G. (2008). Effects of Medicago truncatula genetic diversity, rhizobial competition, and strain effectiveness on the diversity of a natural Sinorhizobium species community. Appl. Environ. Microbiol. 74, 5653-5661. doi: 10.1128/AEM.01107-08

Reeve, W., Chain, P., O’Hara, G., Ardley, J., Nandesena, K., Bräu, L., et al. (2010). Complete genome sequence of the Medicago microsymbiont Ensifer (Sinorhizobium) medicae strain WSM419. Stand. Genomic Sci. 2, 77-86. doi: 10.4056/sigs.43526

Rome, S., Brunel, B., Normand, P., Fernandez, M., and Cleyet-Marel, J. C. (1996a). Evidence that two genomic species of Rhizobium are associated with Medicago truncatula. Arch. Microbiol. 165, 285-288. doi: 10.1007/s002030050328

Rome, S., Fernandez, M. P., Brunel, B., Normand, P., and Cleyet-Marel, J. C. (1996b). Sinorhizobium medicae sp. nov., isolated from annual Medicago spp. Int. J. Syst. Bacteriol. 46, 972-980. doi: 10.1099/00207713-46-4-972

Schuize, J., Adgo, E., and Merbach, W. (1999). Carbon costs associated with $\mathrm{N}_{2}$ fixation in Vicia faba L and Pisum sativum L. over a 14-day period. Plant Biol. 1, 625-631. doi: 10.1111/j.1438-8677.1999.tb00273.x

Silsbury, J. H. (1977). Energy requirement for symbiotic nitrogen fixation. Nature 267, 149-150. doi: 10.1038/267149a0

Silvente, S., Blanco, L., Camas, A., Ortega, J. L., Ramírez, M., and Lara-Flores, M. (2002). Rhizobium etli mutant modulates carbon and nitrogen metabolism in Phaseolus vulgaris nodules. Mol. Plant Microbe Interact. 15, 728-733. doi: 10.1094/MPMI.2002.15.7.728

Soberon, M., Lopez, O., Morera, C., Girard, M. L., Tabche, M. L., and Miranda, J. (1999). Enhanced nitrogen fixation in a Rhizobium etli $n t r C$ mutant that overproduces the Bradyrhizobium japonicum symbiotic terminal oxidase cbb3. Appl. Environ. Microbiol. 65, 2015-2019.

Sung, S. J., Xu, D. P., and Black, C. C. (1989). Identification of actively filling sucrose sinks. Plant Physiol. 89, 1117-1121. doi: 10.1104/pp.89.4.1117

Sugawara, M., Epstein, B., Badgley, B. D., Unno, T., Xu, L., Reese, J., et al. (2013). Comparative genomics of the core and accessory genomes of 48 Sinorhizobium strains comprising five genospecies. Genome Biol. 14:R17. doi: 10.1186/gb-201314-2-r17 
Tadege, M., Wen, J., He, J., Tu, H., Kwak, Y., Eschstruth, A., et al. (2008). Largescale insertional mutagenesis using the Tnt1 retrotransposon in the model legume Medicago truncatula. Plant J. 54, 335-347. doi: 10.1111/j.1365-313X.2008.03418.x

Talbi, C., Sánchez, C., Hidalgo-Garcia, A., González, E. M., Arrese-Igor, C., Girard, L., et al. (2012). Enhanced expression of Rhizobium etli cbb3 oxidase improves drought tolerance of common bean symbiotic nitrogen fixation. J. Exp. Bot. 63, 5035-5043. doi: 10.1093/jxb/ers101

Terpolilli, J. J., O'Hara, G. W., Tiwari, R. P., Dilworth, M. J., and Howieson, J. G. (2008). The model legume Medicago truncatula A17 is poorly matched for $\mathrm{N}_{2}$ fixation with the sequenced microsymbiont Sinorhizobium meliloti 1021. New Phytol. 179, 62-66. doi: 10.1111/j.1469-8137.2008.02464.x

Udvardi, M. K., Price, G. D., Gresshoff, P. M., and Day, D. A. (1988). A dicarboxylate transporter on the peribacteroid membrane of soybean nodules. FEBS Lett. 231, 36-40. doi: 10.1016/0014-5793(88)80697-5

Vincent, J. M. (1970). A Manual for the Practical Study of Root-Nodule Bacteria. IBP Handbook Number 15. International Biological Programme. Oxford: Blackwell Scientific.

Warren, C. R., and Adams, M. A. (2000). Capillary electrophoresis for the determination of major amino acids and sugars in foliage: application to the nitrogen nutrition of Sclerophyllous species. J. Exp. Bot. 51, 1147-1157. doi: 10.1093/jexbot/51.347.1147

Welham, T., Pike, J., Horst, I., Flemetakis, E., Katinakis, P., Kaneko, T., et al. (2009). A cytosolic invertase is required for normal growth and cell development in the model legume, Lotus japonicus. J. Exp. Bot. 60, 3353-3365. doi: $10.1093 /$ jxb/erp169

Witty, J. F., and Minchin, F. R. (1998). Methods for the continuous measurement of $\mathrm{O}_{2}$ consumption and $\mathrm{H}_{2}$ production by nodulated legume root systems. J. Exp. Bot. 49, 1041-1047. doi: 10.1093/jxb/49.323.1041
Young, J. M. (2003). The genus name Ensifer Casida 1982 takes priority over Sinorhizobium Chen etal. 1988, and Sinorhizobium morelense Wang et al. 2002 is a later synonym of Ensifer adhaerens Casida 1982. Is the combination "Sinorhizobium adhaerens" (Casida 1982) Willems et al. 2003 legitimate? Request for an opinion. Int. J. Syst. Evol. Microbiol. 53, 2107-2110. doi: 10.1099/ijs.0. 02665-0

Young, N. D., Debellé, F., Oldroyd, G. E., Geurts, R., Cannon, S. B., Udvardi, M. K., et al. (2011). The Medicago genome provides insight into the evolution of rhizobial symbioses. Nature 480, 520-524. doi: 10.1038/nature10625

Conflict of Interest Statement: The authors declare that the research was conducted in the absence of any commercial or financial relationships that could be construed as a potential conflict of interest.

Received: 29 April 2014; paper pending published: 13 June 2014; accepted: 05 August 2014; published online: 27 August 2014.

Citation: Larrainzar E, Gil-Quintana E, Seminario A, Arrese-Igor C and González EM (2014) Nodule carbohydrate catabolism is enhanced in the Medicago truncatula A17Sinorhizobium medicae WSM419 symbiosis. Front. Microbiol. 5:447. doi: 10.3389/ fmicb.2014.00447

This article was submitted to Microbial Symbioses, a section of the journal Frontiers in Microbiology.

Copyright (C) 2014 Larrainzar, Gil-Quintana, Seminario, Arrese-Igor and González. This is an open-access article distributed under the terms of the Creative Commons Attribution License (CC BY). The use, distribution or reproduction in other forums is permitted, provided the original author(s) or licensor are credited and that the original publication in this journal is cited, in accordance with accepted academic practice. No use, distribution or reproduction is permitted which does not comply with these terms. 